\title{
Linking Dynamic Capabilities and Healthcare Innovations: A Case Study Approach
}

\author{
(Submission for Doctoral Consortium) \\ Saravana Govindasamy \\ (EDBA Program, Fox School of Business, Temple University, Philadelphia, PA)
}

\begin{abstract}
US Healthcare leaders are confronted with a nexus of healthcare forces that is transforming the industry with new models of care delivery and value-based payments. The health ecosystem is changing swiftly from provider centric to patient/customer centric. The changing healthcare market place, transformational new healthcare model and healthcare reform uncertainties requires healthcare organizations to build new capabilities and explore innovative strategies to survive and thrive in these difficult economic times and the volatile healthcare environment. The dynamic capabilities (DC) - a powerful strategic management framework considered most relevant for businesses in highly competitive and volatile sectors can help healthcare organizations win sustainable competitive advantage at the enterprise level by maximizing value for patients: that is, achieving the best outcomes at the lowest cost. This research paper examines the dynamic capability (DC) literature in the context of healthcare industry by exploring the relationships between the dynamic capabilities (learning, coordinating and integrating) with different types of innovations (product, process and structure) and proposes a framework to map the innovation space and operationalize innovation across the continuum of care in the hospitals.
\end{abstract}

\section{INTRODUCTION}

This is an era of transformation for US healthcare system. A 2015 survey of 19 CEOs of large hospitals and health systems by the Deloitte Center for Health Solutions found that CEOs believe that "Value Based Care (VBC) will reshape the future of health care" and that it will "drive further consolidation (acquisition and affiliations) among hospitals and physicians." However, the CEOs noted they were "not sure when to shift the business model and whom to partner with to be successful in VBC."

Innovation is seen as a key means by which healthcare organizations can accomplish this transformation. Though most of the hospitals sensed the market forces and decided to invest in innovations, only some are succeeding in developing the capabilities that are required to seize this opportunity. At most academic medical centers innovations remains more of a future vision than a daily reality and for smaller or community-based providers, this gap is even wider. The key questions the healthcare leaders are confronted with are:

- What type of innovations should we pursue and why?

- What are the capabilities that are required to deliver these innovations?

- How fast we can harness the innovations - through external partnerships or developing capabilities in house?

- What will help/hinder the dynamic capabilities from successfully becoming a part of everyday practices in my hospital?

While prior research recognizes the importance of dynamic capabilities in innovation on a conceptual level, very little research has empirically identified the role of dynamic capabilities related to different types of innovations in healthcare industry. The objective of this paper is to address this knowledge gap and to explore the relationships between dynamic capabilities and different types of innovations by taking the holistic view of the dynamic capabilities and innovation theory in tandem. This study investigates what kind of capability innovation combinations are to be found, and in whether differences in dynamic capabilities explain the adoption of specific types of innovations in healthcare setting. Such knowledge has considerable relevance to business practitioners since it may be able to indicate what kind of capabilities should be fostered in order to generate desirable innovations.

Not only does it provide a template for understanding where to focus efforts to create lasting competitive advantage, it illuminates the specific causes of the mismatch between hospitals' archetypal capabilities/leadership skills and the 


\section{SUBMISSION FOR DOCTORAL CONSORTIUM}

demands of an evolving business environment characterized by increased competition and uncertainty.

\section{LITERATURE REVIEW}

Dynamic capabilities are a special class of capabilities concerned with change and innovation. Dynamic capabilities help explain how organizations enhance and sustain performance in rapidly changing environments by creating, extending, or modifying their resource base through investment and other managerial interventions. Dynamic capabilities have also been conceptualized as flexibility and adaptability of resources and routines (Evans et al., 2017).

\subsection{Operational \& Dynamic Capabilities}

Prior research has distinguished between operational (or ordinary) and dynamic capabilities (Winter, 2003, Helfat et al., 2007). An operational capability enables the firm to perform an activity on an on-going basis using more or less the same techniques on the same scale to support existing products and services for the same customer population. Such a capability is ordinary in the sense of maintaining the status quo (that is not out of the ordinary; (Winter, 2003) refer to these as zero order capabilities.

In contrast, a dynamic capability is the one that enables a firm to alter how it currently makes it living (Helfat \& Winter, 2011). (Teece, 1997) defined dynamic capabilities as "the firm's ability to integrate, build, and reconfigure internal and external competences to address rapidly changing environments in which there is deep uncertainty." Teece also points out that dynamic capabilities are more than simply best practices or routine capabilities. They are uncommon competences that are difficult to imitate.

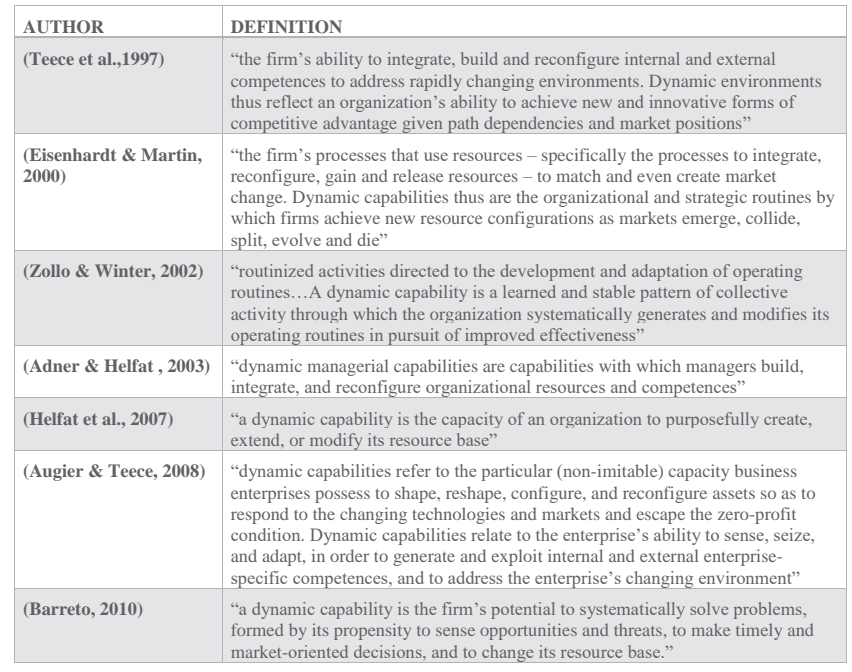

Table 1: Dynamic Capabilities Definitions
(Teece, 2007) introduced a framework categorizing a firm's dynamic capabilities in three groups, related to sensing opportunities and threats, seizing opportunities, and reconfiguring the firm's asset base.

\subsubsection{Sensing}

Successful sensing enables an organization to focus on where it will be tomorrow, rather than on where it is today. But sensing is not easy and is difficult to spot emerging trends. Sensing involves scanning, searching, and understanding customer needs, latent demand, technological possibilities, local and non-local markets, and the probable supplier and competitor responses (Agwunobi \& Osborne, 2016).

\subsubsection{Seizing}

The organization's ability to sense a market opportunity does not mean that it can seize it effectively. The managerial skills needed to sense are quite different from those needed to seize and those needed to reconfigure. To seize opportunities effectively, enterprises must have the ability to make highquality investment decisions; they must have or create the right business model; and they must maintain and improve technological competences and complementary assets. The challenge hospitals face includes their hierarchical structures which slow decision making and lead to bidirectional loss of information.

\begin{tabular}{|l|l|}
\hline CAPABILITY & DEFINITION \\
\hline $\begin{array}{l}\text { Learning } \\
\text { capability }\end{array}$ & $\begin{array}{l}\text { The ability to revamp existing } \\
\text { operational capabilities with new } \\
\text { knowledge }\end{array}$ \\
\hline $\begin{array}{l}\text { Integrating } \\
\text { capability }\end{array}$ & $\begin{array}{l}\text { The ability to embed new knowledge } \\
\text { into the new operational capabilities by } \\
\text { creating a shared understanding and } \\
\text { collective sense-making }\end{array}$ \\
\hline $\begin{array}{l}\text { Coordinating } \\
\text { capability }\end{array}$ & $\begin{array}{l}\text { The ability to orchestrate and deploy } \\
\text { tasks, resources, and activities }\end{array}$ \\
\hline
\end{tabular}

Table 2: Dynamic Capabilities Dimensions Definitions (Pavlou \& Sawy, 2011)

\subsection{Innovation}

The largely accepted definition of Innovation among researchers in the field is "the intentional introduction and application within a role, group, or organization, of ideas, processes, products or procedures, new to the relevant unit of adoption, designed to significantly benefit the individual, the group, or wider society". This encapsulate three key dimensions of innovation: 1) novelty 2) an application component 3) an intended benefit (Omachonu et al., 2010). 
Innovation is the successful implementation of a novel idea in a way that creates compelling value for some or all of the stakeholders (Varkey, et al., 2008).

"Healthcare innovation can be defined as the introduction of a new concept, idea, service, process, or product aimed at improving treatment, diagnosis, education, outreach, prevention and research, and with the long term goals of improving quality, safety, outcomes, efficiency and costs" (Omachonu et al., 2010).

\subsection{Innovation Types}

Innovations in health care typically are related to product, process, or structure (Varkey, et al., 2008).

\subsubsection{Product}

The product is what the customer pays for and typically consists of goods or services. Clinical procedure innovations belong to the category of product innovations.

\subsubsection{Process}

Process innovation entails innovations in the production or delivery method. The customer does not usually pay directly for process, but the process is required to deliver a product or service and to manage the relationship with the various stakeholders.

\subsubsection{Structure}

Structural innovations usually affect the internal and external infrastructure and create new business models. By their nature, structural changes are more likely to be disruptive because they represent major changes in the way health care is delivered. Some organizations are exploring strategic partnerships like innovation centers, incubators, and external technology arrangements to achieve the organization innovation goals.

\section{DC FRAMEWORK}

A dynamic capabilities (DC) framework in the context of healthcare has been proposed to explore the relationship between organizational determinants of innovation, types of innovations, and the measures of healthcare organizations performance.

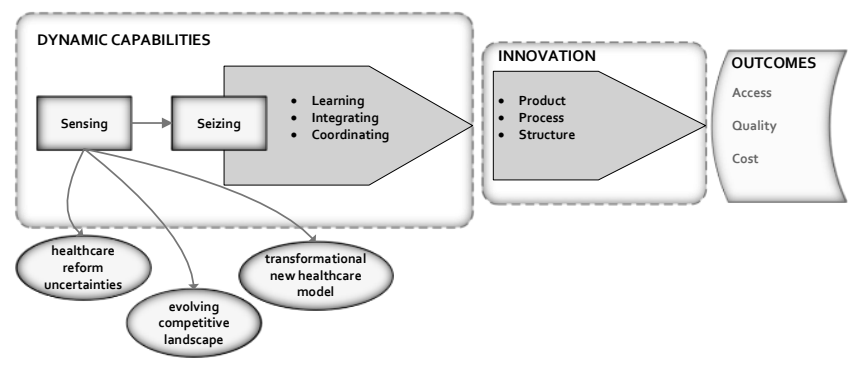

Figure 1: Dynamic Capabilities Framework in Healthcare

\section{APPROACH}

This research paper first examines the dynamic capability (DC) literature in the context of healthcare industry to propose a framework to explore the antecedents and consequences of adoption of customer centric innovations. Second, this paper explores the relationship between the dynamic capabilities (learning, coordinating and integrating capabilities) with different types of innovation (product, process and structure innovations) and its impact on the performance of the healthcare organizations.

\section{CONCEPTUAL MODEL}

A conceptual model is developed to operationalize the defined constructs. The model links the three dynamic capabilities (learning, integrating, and coordinating) to the three innovation types (process, product, and structure) and to the two organization types (academic, and community hospitals).

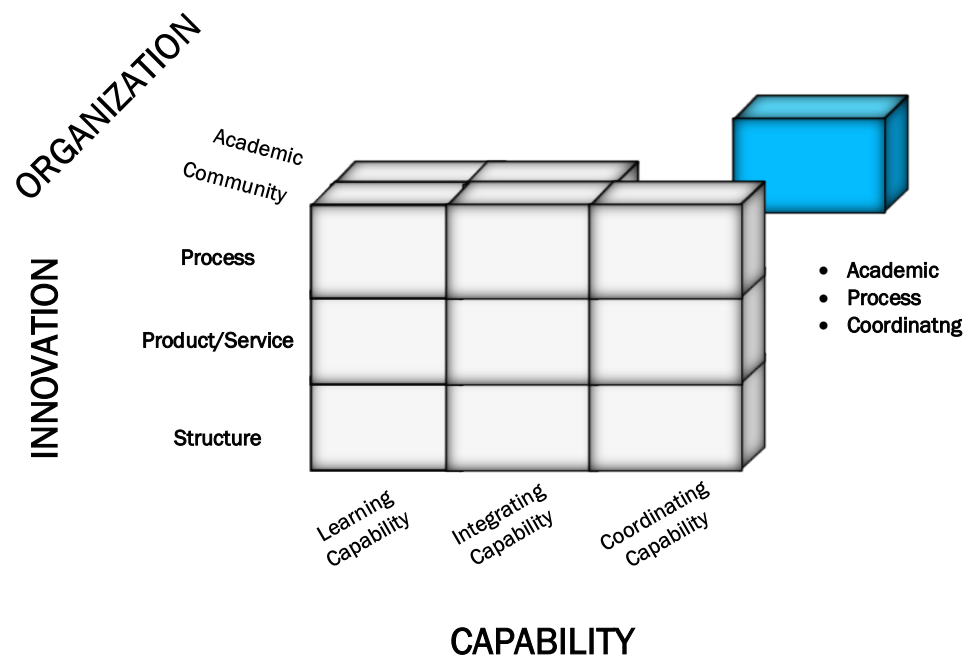

Figure 2: Models to explore capabilities and innovations

\section{METHODOLOGY}

Applying a case study method to investigate dynamic capability building processes in the context of collaboration is not new in the literature. A main finding from prior research is that competence development over time is to a high extent influenced by the firm's close and regular interactions with their immediate customers, as well as some third parties in their network of exchange relationship (Agarwal et al., 2014). The case study method is particularly suitable for practice-oriented fields and answers the "how or why" some social phenomenon works (Yin, R.K., 2015). 
The case study analysis is performed following four steps: (1) Pilot interviews for questionnaire development; (2) Case selection; (3) Data gathering collection and organizing; (4) Analysis of data.

The analysis focused on two case studies of Pennsylvania hospitals (1 academic hospital and 1 community hospital). Before starting the collecting of the most relevant data, a pilot was conducted with hospital leaders (administrators and physician leaders) to fine tune the interview protocol and guiding questions. To support the results obtained, 8 unstructured interviews were conducted.

The semi-structured interviews were administered through a set of open-ended questions and conducted on the interviewees' company premises. the interviews lasted, on average, $45 \mathrm{~min}$; they were recorded and then verbatim transcribed. The data analysis is performed using Temi.com for transcription and nVivo for analysis.

\section{PRELIMINARY FINDINGS}

The key determinants of innovations in hospitals are a) learning capability and b) integrating capability. The organizations studied are primarily looking into product/service and process innovations across the basic research and sustaining innovation domains.

\section{MANAGERIAL IMPLICATIONS}

The integrated dynamic capability framework presented in this study, linking capabilities and innovations help hospital managers and executives to identify the differences between operational (exploitative) and dynamic (explorative) capabilities to designing and implementing new combinations of technologies, human skills, and capital assets.

\section{DOCTORAL CONSORTIUM PANEL}

The doctoral consortium provides an opportunity to interact with outstanding mentors and fellow doctoral students from other institutions. The feedback from the mentors, experts and thought leaders in the healthcare industry would be immensely valuable and make this research empirically rigorous and practically relevant.

\section{REFERENCES}

Adner, R., \& Helfat, C. E. (2003). Corporate effects and dynamic managerial capabilities. Strategic Management Journal, 24(10), 10111025.https://doi.org/10.1002/smj.331

Agarwal, R., Selen, W., Sajib, S., \& Scerri, M. (2014). Dynamic capability building in service networks: An exploratory case study. Journal of New Business Ideas and Trends, 12(1), 27-41.

Agwunobi, A., \& Osborne, P. (2016). "Dynamic capabilities and healthcare: A framework for enhancing the competitive advantage of hospitals", California Management Review, 58(4), 141-161. doi:10.1525/cmr.2016.58.4.141.

Augier, M., \& Teece, D. J. (2008). Strategy as Evolution with Design: The Foundations of Dynamic Capabilities and the Role of Managers in the Economic System. Organization Studies, 29(8-9), 1187-1208. https://doi.org/10.1177/0170840608094776

Barreto, I. (2010). Dynamic Capabilities: A Review of Past Research and an Agenda for the Future. Journal of Management, 36(1), 256-280.

Eisenhardt, K. M., \& Martin, J. A. (2000). Dynamic capabilities: What are they? Strategic Management Journal, 21, 1105-1122

Evans, J., Brown, A., \& Baker, G. (2017). Organizational knowledge and capabilities in healthcare: Deconstructing and integrating diverse perspectives. SAGE Open Medicine, 5, SAGE Open Medicine, 2017, Vol.5.

Helfat, C., Winter, S. (2011), "Untangling Dynamic and Operational Capabilities: Strategy for the (n)everchanging world", Strategic Management Journal, 29:1451-1463.

Helfat CE, Finkelstein S, Mitchell W, Peteraf MA,Singh H, Teece DJ, Winter SG. (2007), "Dynamic Capabilities: Understanding Strategic Change in Organizations", Blackwell Publishing, Malden, MA.

Omachonu, V. K., \& Einspruch, N. G. (2010). Innovation in healthcare delivery systems: a conceptual framework. The Innovation Journal: The Public Sector Innovation Journal, 15(1), 1-20.

Pavlou, P. A., \& El Sawy, O. A. (2011). Understanding the elusive black box of dynamic capabilities. Decision Sciences, 42(1), 239-273.

Teece, D., \& Pisano, G. (1994). The dynamic capabilities of firms: An introduction. Industrial and Corporate Change, 3, 537.

Teece, D. J. (2007). "Explicating dynamic capabilities: The nature and microfoundations of (sustainable) enterprise performance", Strategic Management Journal, 28(13), 1319-1350. doi:10.1002/smj.640.

Teece, D., Peteraf, M., \& Leih, S. (2016). "Dynamic capabilities and organizational agility: Risk, uncertainty, 


\section{SUBMISSION FOR DOCTORAL CONSORTIUM}

and strategy in the innovation economy", California Management Review, 58(4), 13-35. doi:10.1525/cmr.2016.58.4.13.

Varkey, P., Horne, A., \& Bennet, K. (2008). Innovation in Health Care: A Primer. American Journal of Medical Quality, 23(5), 382-388.

Yin, R.K. (2014). Case study research: Design and methods. In Essential Guide to Qualitative Methods in Organizational Research. California: SAGE Publications.

Zollo, M., \& Winter, S. G. (2002). Deliberate Learning and the Evolution of Dynamic Capabilities. Organization Science, 13(3), 339-351.

https://doi.org/10.1287/orsc.13.3.339.2780 